\title{
Densidade de Enterococcus sp em águas recreacionais e areias de praias do município de São Vicente-SP, Brasil e sua relação com parâmetros abióticos Density of Enterococcus sp in recreational waters and beach sand
in São Vicente-SP, Brazil and its relationship to abiotic parameters
}

Aline Bartelochi Pinto*

Cristina Rocha Pereira**

Ana Júlia Fernandes Cardoso de Oliveira***

\section{Resumo}

As cidades litorâneas atraem inúmeros turistas pela sua beleza cênica e atrativos recreacionais, incrementando a fonte de renda dos municípios. Dessa forma, é evidente a necessidade de programas de monitoramento da qualidade de suas praias, a fim de assegurar a saúde dos banhistas. Apesar de haver um monitoramento eficaz para as águas recreacionais marinhas, ainda não existem, no Brasil, programas que atestem a qualidade das areias das praias. Nesse sentido, o presente estudo objetivou analisar a densidade de bactérias do gênero Enterococcus nas areias e águas de duas praias do município de São Vicente-SP, Brasil correlacionando com parâmetros abióticos (temperatura, salinidade, granulometria, matéria orgânica e variação de maré). Amostras de água e areia foram coletadas durante o mês de fevereiro de 2006 nas praias do Gonzaguinha e da Ilha Porchat, e as densidades das bactérias, determinadas com base na técnica de membrana filtrante. Temperatura e salinidade foram medidas in situ com o auxílio de um termômetro e um refratômetro, enquanto que granulometria e matéria orgânica foram determinadas em laboratório, de acordo com os métodos descritos por Suguio e Dean. Houve diferenças significativas entre as densidades encontradas na água e nas areias ( $p=0.004)$, sendo aproximadamente 20 vezes superior na areia das praias do Gonzaguinha. Resultado semelhante foi obtido para as amostras das praias da Ilha Porchat, sendo as densidades encontradas nas areias cerca de três vezes superior às encontradas nas amostras de água. Em ambas as praias, salinidade e temperatura correlacionaram-se de maneira negativa com as densidades obtidas, o que sugere que há um efeito deletério desses parâmetros sobre a população bacteriana. O presente estudo demonstra que há uma grande necessidade de estabelecimento de programas de monitoramento para areias de praias, visto que atualmente a avaliação da qualidade das praias é parte importante de programas de gerenciamento costeiro integrado.

Palavras-chave: Saúde Pública. Areia. Indicadores de Contaminação. Litoral.

\begin{abstract}
Coastal cities attract a large number of tourists for their beautiful landscape and recreational activities, increasing the municipalities' income source. Thus, a need is clear for the establishment of beach quality monitoring programs to ensure bathers health. Although there is an effective monitoring program for recreational waters in Brazil there are no programs to certify the quality of beach sands. In this sense, the aim of this work was to analyze the density of bacteria from the genus Enterococcus in both sand and water from two beaches from São Vicente, São Paulo (Brazil) and correlate these densities to abiotic parameters such as: temperature, salinity, particle size, organic matter and tides). Water and sand samples were collected during February 2006 on the beaches of Gonzaguinha e Ilha Porchat and bacterial densities were determined by membrane filter technique. Temperature and salinity were measured in situ with a thermometer and a refractometer while particle size and organic matter were determined according to methods described by Suguio and Dean. There were significant differences between densities found in water and sand ( $\mathrm{p}=0.004)$, being approximately 20 times higher in Gonzaguinha's beach sands. Similar results were found for Ilha Porchat beach samples, being the densities found in sand 3 times greater than those found in water. Both beaches showed a negative correlation between bacterial densities and salinity and temperature, suggesting a deleterious effect of these parameters on the bacterial community. On the other hand, no correlation was found between organic matter and particle size and bacterial densities. This work demonstrates that there is a great necessity for monitoring beach sand since the evaluation of beach quality is an important part of integrated coastal management programs.
\end{abstract}

Keywords: Public Health. Sand. Pollution Indicators. Coasts.

\footnotetext{
* Bióloga. Mestre em Microbiologia. Doutoranda do Programa de Pós-Graduação em Microbiologia Aplicada, Instituto de Biociência da UNESP de Rio Claro, Rio Claro-SP, Brasil. E-mail: aline.bartelochi@gmail.com

** Bióloga. Mestranda em Microbiologia do Programa de Pós-Graduação em Microbiologia Aplicada, Instituto de Biociência da UNESP de Rio Claro, Rio Claro-SP, Brasil. E-mail: cristinarochapereira@yahoo.com

*** Bióloga. Doutora e Mestre em Oceanografia Biológica pela USP. Professor Assistente Doutor da UNESP, Campus Experimental do Litoral Paulista, São Vicente-SP, Brasil. E-mail: ajuliaf@clp.unesp.br

As autoras declaram não haver conflito de interesses.
} 


\section{INTRODUÇÃO}

O uso das águas costeiras para atividades recreativas, no Brasil, atrai pessoas para as regiões costeiras e também aumenta o turismo, representando a principal fonte de renda dos municípios. Nesse sentido, torna-se evidente a necessidade de manter a qualidade das águas recreacionais marinhas, no entanto o crescimento da populainfraestruturas de saneamento, e os efluentes são liberados diretamente no mar, provocando um incremento nas doenças de veiculação hídrica ${ }^{1}$.

Águas recreacionais marinhas podem conter organismos patogênicos e não patogênicos cujas fontes podem ser a presença de esgoto não tratado, lixo, águas de drenagem, urina e fezes de animais. A presença desses patógenos, tanto na areia quanto na água, consiste em uma ameaça à saúde dos banhistas, que podem estar sujeitos a doenças, como gastroenterites, doenças respiratórias, infecções de pelo e ouvidos², entre outras.

Muitos estudos têm demonstrado que as areias de praias podem conter maiores densidades de bactérias que a coluna d'água ${ }^{3,4}$, uma vez que encontram nesse ambiente condições favoráveis de nutrientes ${ }^{5}$, proteção contra a luz solar ${ }^{6}$ e contra a predação por protozoários ${ }^{7}$. De fato, as areias de praias podem se comportar como elemento passivo no que diz respeito ao acúmulo de poluentes e podem tornar-se contaminadas por lixo, dejetos de animais ou pela própria água, e, dessa forma, o contato prolongado talvez apresente um risco maior à saúde da população.

No Estado de São Paulo, o monitoramento das águas é realizado pela Companhia de Tecnologia e Saneamento Ambiental (CETESB), de acordo com a resolução n. 274 do Conselho Nacional do Meio Ambiente $(\mathrm{CONAMA})^{8}$, que determina que águas recreacionais sejam avaliadas de acordo com as densidades de Escherichia coli, Enterococcus sp e coliformes totais. Entretanto, não existe, até o momento, monitoramento nem legislação para atestar a qualidade microbiológica das areias das praias. Porém, como os banhistas tendem a passar grande parte do tempo nas areias e diante da possibilidade de tais areias apresentarem um grau significativo de contaminação, torna-se evidente a necessidade da realização de mais estudos, a fim de que se possa

estabelecer padrões microbiológicos, seus limites e programas de monitoramento das areias.

Nesse sentido, os objetivos do presente estudo foram: (i) estudar a variação espaço-temporal e a influência de fatores abióticos (salinidade, temperatura, granulometria e matéria orgânica) nas densidades de bactérias do gênero Enterococcus na água e nas areias e praias com diferentes graus de impacto; e (ii) avaliar a potencialidade das areias como fonte de contaminação por patógenos e, desse modo, estabelecer a necessidade de indicadores microbiológicos, padrões e redes de monitoramento para tais ambientes.

\section{MÉTODO}

\section{Área de Estudo}

O município de São Vicente está localizado na Baixada Santista, litoral central do Estado de São Paulo (Brasil) (Figura 1). Possui área dividida entre o continente e a Ilha de São Vicente (completamente ocupada), com $6 \mathrm{~km}$ de extensão de praias. Nesse município, existe uma estação de tratamento de esgoto que funciona de forma precária e é responsável por $100 \%$ do tratamento dos 56\% de esgoto coletado. Parte do esgoto coletado é direcionada para o emissário submarino de Santos ${ }^{9}$ e lançado ao mar após o tratamento.

A população flutuante constitui um contingente expressivo, chegando a atingir, no verão e carnaval, mais que o dobro da população residente. Esse aumento sazonal provoca um aumento na carga de esgotos domésticos na região, o que, por fim, acarreta em uma piora na qualidade das águas das praias bem como das areias.

Figura 1. Mapa da América do Sul e do Brasil, indicando a localização da Baixada Santista. Detalhe da Baía de Santos com a localização das Praias do Gonzaguinha e da Ilha Porchat, no Município de São Vicente-SP

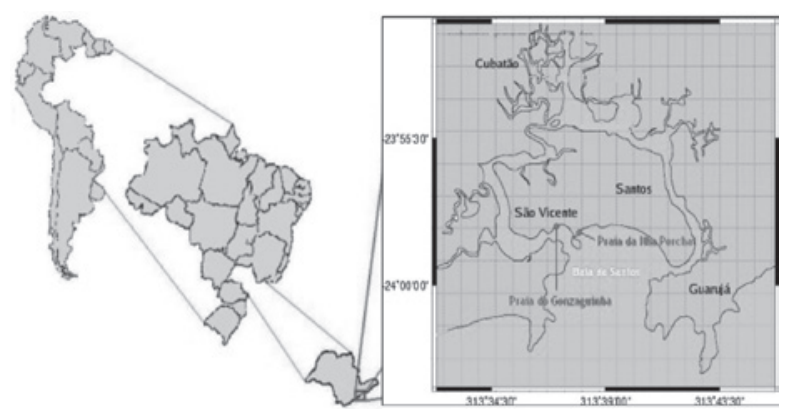




\section{Coleta e processamento das amostras}

Foram realizadas coletas durante o mês de fevereiro de 2006, em duas praias do município de São Vicente, Gonzaguinha e Ilha Porchat. Amostras de água foram coletadas durante os períodos de maré enchente e vazante em 5 pontos no Gonzaguinha e 3 pontos na Ilha Porchat, com auxílio de frascos esterilizados. Amostras de areia foram coletadas em pontos imediatamente correspondentes aos pontos de água em duas zonas distintas: zona úmida e zona seca, com auxílio de uma espátula estéril.

As amostras coletadas foram mantidas sob refrigeração até o processamento no Laboratório de Microbiologia Marinha da UNESP - Campus Experimental do Litoral Paulista.

As densidades de bactérias do gênero Enterococcus foram determinadas com base na técnica de Membrana Filtrante ${ }^{10}$, utilizando como meio de crescimento o Agar MEnterococcus. Foram filtrados volumes de 50, 25, 10, 5 e $1 \mathrm{ml}$ para as amostras de água. Amostras de areia foram pesadas e acrescidas de água destilada estéril $(1: 10)$ e submetidas à agitação por 10 minutos para lavagem e completa extração das bactérias da amostra e, posteriormente, filtrados volumes de 100, 50, 25, 10 e $1 \mathrm{ml}$. As placas foram incubadas a $37^{\circ} \mathrm{C}$ por $24 / 48 \mathrm{~h}$ e monitoradas quanto ao crescimento de colônias típicas que foram transferidas para o meio de confirmação Enterococosel caldo.

Em todos os pontos amostrados, foram registrados valores de salinidade com auxílio de um refratômetro portátil e temperatura com auxílio de um termômetro.

A análise granulométrica foi realizada de acordo com o método descrito por Suguio ${ }^{11}$, e as classificações granulométricas feitas de acordo com a Associação Brasileira de Normas Técnicas (ABNT) NBR NM 248/2003 ${ }^{12}$. Já a análise de matéria orgânica foi realizada de acordo com o método descrito por Dean ${ }^{13}$.

\section{Análise Estatística}

Os dados gerados foram analisados com o auxílio do programa Statistica 7 (Statsoft), utilizando-se análises de correlação e teste-t a 95\% de intervalo de confiança para analisar as possí- veis relações entre as densidades bacterianas e os fatores abióticos avaliados.

\section{RESULTADOS}

Na praia do Gonzaguinha, considerada mais impactada pelas análises realizadas pela CETESB, a média das densidades bacterianas permaneceu, de maneira geral, abaixo dos valores estabelecidos pela legislação brasileira (400 UFC $\mathrm{ml}^{-1} \mathrm{em}$ uma única amostragem). Entretanto, em uma ou mais amostragens, houve densidades elevadas, sendo que o valor máximo atingido foi de 800 UFC $\mathrm{ml}^{-1}$ (Figura 2). Houve diferenças significativas entre as densidades encontradas na água e nas areias $(p=0.004)$, sendo que altas densidades foram encontradas tanto na areia seca quanto na areia úmida. Entretanto, as maiores densidades foram encontradas na areia seca (valor máximo de 15.600 UFC $\mathrm{ml}^{-1}$ ) (Figura 2). Houve diferença significativa entre as marés alta e baixa, sendo maiores densidades encontradas na maré baixa. Em contrapartida, não foi observada diferença entre as densidades encontradas entre as areias úmida e seca.

Houve correlação entre as densidades encontradas na areia e na água $(\mathrm{p}=0.010)$, sugerindo uma possível troca entre esses dois ambientes.

Figura 2. Densidade de bactérias do gênero Enterococcus na água e nas areias da praia do Gonzaguinha, São Vicente-SP
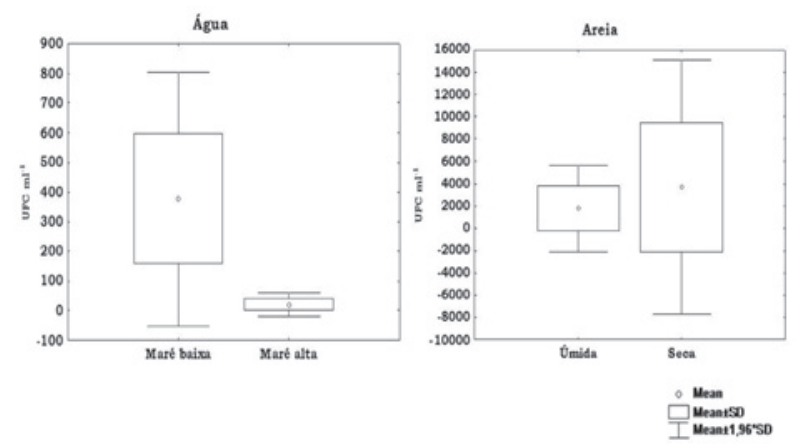

Observou-se uma correlação inversa entre valores de salinidade e densidades bacterianas na água ( $r=-0,6995)$, sendo que valores de salinidade baixos corresponderam ao aumento nas densidades bacterianas. Essa relação também foi observada para valores de temperatura $(r=-0,5854)$. De maneira geral, pode-se observar que tanto a 
salinidade quanto a temperatura possuem efeitos negativos sobre a população bacteriana presente na coluna d'água. Tal relação não foi comprovada comparando-se os fatores abióticos às densidades obtidas para as areias.

Quanto à classificação granulométrica, a praia do Gonzaguinha possui $97.6 \%$ de areia fina e $1.4 \%$ de areia média, porém essa constituição aparentemente não possui influência nas densidades obtidas no presente estudo. Da mesma forma, a porcentagem de matéria orgânica também não possui relação significativa com as densidades bacterianas nas areias $(p=0,426)$.

Na praia da Ilha Porchat, considerada menos impactada, as médias das densidades bacterianas mantiveram-se abaixo do permitido por lei, mas houve uma amostragem em que se obtiveram densidades de 960 UFC ml-1. Da mesma forma que para a praia do Gonzaguinha, a praia da Ilha Porchat apresentou maiores valores para as areias que para as amostras de água, sendo que maiores valores foram encontrados na areia seca (2960 UFC $\mathrm{ml}^{-1}$ ), em relação à areia úmida (Figura 3). Comparando-se as duas praias, podemos observar que as densidades bacterianas, ainda que elevadas, nas areias da Ilha Porchat foram significativamente menores que na praia do Gonzaguinha.

Figura 3. Densidade de bactérias do gênero Enterococcus na água e nas areias da praia da Ilha Porchat, São Vicente-SP
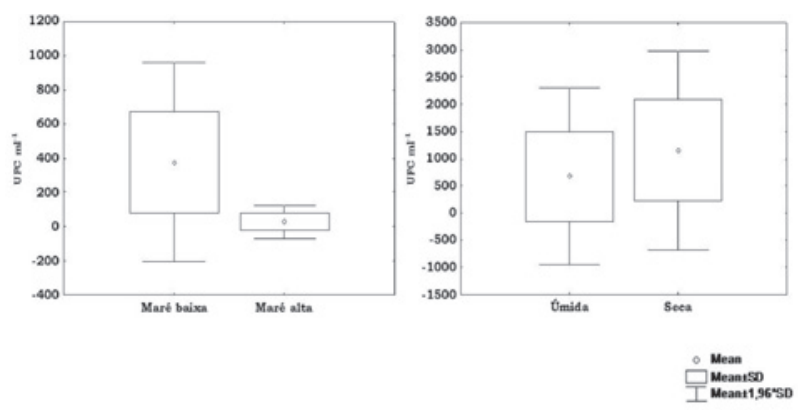

Houve diferenças significativas entre maré enchente e vazante $(p=0,0018)$, bem como para as densidades encontradas na coluna d'água e nas areias ( $p=0,005596)$. Observou-se uma relação negativa entre valores de salinidade e densidades bacterianas na água com diferenças significativas $(p=0,00010)$, bem como para valores de temperatura $(p=0,000087)$. Em contrapartida, a constituição granulométrica da praia da Ilha Porchat também não demonstrou ter influência sobre as densidades obtidas (100\% de areia fina).

Ao contrário do observado para a praia do Gonzaguinha, na praia da Ilha Porchat houve uma relação significativa entre a porcentagem de matéria orgânica e as densidades bacterianas ( $p=0,003975)$, o que demonstra que, para essa praia, a matéria orgânica tem influência na sobrevivência das bactérias no sedimento.

\section{DISCUSSÃO}

Segundo a resolução n. 274, de 29 de novembro de 2000, do CONAMA, é considerada adequada ao banho a praia que apresentar densidade de Enterococcus até 400 UFC $100 \mathrm{ml}^{-1}$, 2500 UFC $100 \mathrm{ml}^{-1}$ de coliformes fecais (termotolerantes), ou, ainda, 2000 UFC $100 \mathrm{ml}^{-1}$ de Escherichia coli em uma única amostra. De acordo com os dados da CETESB ${ }^{9}$, a praia do Gonzaguinha, no período desde 1997 até o presente ano, manteve-se imprópria para banho, enquanto que a qualidade da água na praia da Ilha Porchat foi considerada regular, durante o mesmo período, excetuando-se o ano de 2002, durante o qual sua qualidade foi considerada boa. Os resultados obtidos no presente estudo, em ambas as praias, corroboram os dados fornecidos pelos boletins semanais emitidos por tal órgão, incluindo-se a semana na qual foram efetuadas as análises.

A variação temporal da densidade de bactérias na água do mar, observada no presente estudo, em ambas as praias, pode estar refletindo o aporte de água doce nessas águas, uma vez que os valores de salinidade foram inversamente proporcionais às densidades de bactérias, e as maiores densidades de Enterococcus foram obtidas na maré baixa. Durante a maré baixa, todos os corpos de água, inclusive aqueles que recebem carga orgânica, têm uma maior vazão, sendo despejados na água do mar. Além disso, a sobrevivência de microrganismos patógenos na água do mar diminui com o aumento da salinidade ${ }^{14,15}, \mathrm{o}$ que explica a correlação negativa entre a salinidade e as densidades bacterianas na água obtida no presente estudo.

A praia do Gonzaguinha, além de estar localizada próxima à desembocadura de um estuário que recebe esgoto doméstico em grande parte de sua extensão, também recebe fontes 
não pontuais de contaminação, como as águas de drenagem continental, que acarretam aumento na densidade de microrganismos, inclusive os patogênicos, na água do mar $^{16}$.

Outro fator importante é a localização da praia do Gonzaguinha, que se encontra em uma baía, o que faz com que a circulação da água seja reduzida, bem como a dispersão de poluentes ${ }^{17,18}$.

Já a fisiografia da praia da Ilha Porchat favorece uma maior circulação por ser um sistema aberto e que não apresenta fontes pontuais de descarga de esgotos comparativamente à praia do Gonzaguinha. Dessa forma, além do aporte de carga orgânica ser significativamente menor, o transporte desse material pela água do mar para fora da costa favorece processos como a deposição e a diluição dos contaminantes, inclusive microrganismos ${ }^{16}$. Esses fatores podem explicar as baixas densidades de Enterococcus observadas para essa praia.

No presente trabalho, à semelhança dos resultados obtidos por outros autores ${ }^{19}$, não foi observada relação entre a temperatura e as densidades de microrganismos na coluna de água, mas cabe salientar que a influência da temperatura nas densidades e na sobrevivência de bactérias pode ter sido mascarada pela incidência de luz ${ }^{20,21,22}$.

Tanto na Praia do Gonzaguinha quanto na da Ilha Porchat, as densidades de Enterococcus foram maiores nas amostras de areia comparativamente àqueles obtidos para a coluna d'água. Elmanama, et al ${ }^{23}$ obtiveram resultados semelhantes para as praias de Gaza, assim como Bonilla, et $\mathrm{al}^{24} \mathrm{em}$ estudo conduzido na Flórida, onde a densidade de bactérias nas areias foi 2 a 23 vezes maior que na coluna de água.

Estudos feitos por Davies-Colley, et al ${ }^{6}$ têm demonstrado que indicadores fecais, na água do mar, sofrem inativação causada pelos raios solares e estão expostos à ação de bacteriófagos, baixa quantidade de nutrientes, predação e competição com organismos autóctones. Dessa forma, as areias de praias agiriam como protetoras para tais microrganismos. De fato, as areias de praia constituem um ambiente protetor, atenuando a exposição desses microrganismos aos raios solares e diminuindo a bacteriovoria e competição, além de possibilitarem a sobrevivência dessas bactérias, pois elas podem se aderir a partículas do sedimento ${ }^{25}$. Devido à alta quantidade de detritos orgânicos associados a essas partículas, bactérias podem sobreviver nesse ambiente por longos períodos ${ }^{26,27,28}$, uma vez que encontram condições favoráveis.

Areias de praia, por se caracterizarem como um reservatório de microrganismos ${ }^{29}$, também podem ser responsáveis pela recontaminação de águas adjacentes ${ }^{30}$, uma vez que bactérias da areia podem ser resuspensas na coluna de água por intempéries, pela movimentação de barcos ou veículos nas praias, pela ação das ondas ou pela própria atividade de recreação.

Foi observada, também, uma maior abundância de organismos na areia seca comparativamente à areia úmida. Bonilla, et $\mathrm{al}^{24}$, em estudos conduzidos na Flórida, encontraram resultado semelhante, em que a abundância de bactérias na areia seca foi dez vezes maior que na areia úmida.

A correlação positiva observada no presente trabalho, entre a abundância de microrganismos na água e na areia úmida, foi também obtida por Sato, et $\mathrm{al}^{31}$ em estudo feito em 16 praias no litoral de São Paulo. Menores densidades de indicadores de contaminação fecal na areia úmida provavelmente ocorrem devido às trocas entre água do mar e a areia úmida, que, aparentemente, compõe um reservatório para esses organismos, contribuindo para seu aumento na coluna de água quando ocorrem eventos que causam resuspensão da areia ${ }^{8}$.

A ausência de correlação entre a variação das densidades de bactérias na areia seca e na água do mar indica que a microbiota desse ambiente é proveniente de fontes diferentes do que aquelas que contaminam a água e a areia úmida. A areia seca pode ter como fonte principal de contaminação as fezes e secreções de humanos e de animais e o lixo presentes nas praias. A praia do Gonzaguinha possui muitos frequentadores que levam seus animais para a praia, além de acumular muito lixo durante o dia ${ }^{32}$.

De acordo com Crapez ${ }^{33}$, a composição e o tamanho dos grãos no sedimento possuem correlação negativa com as densidades bacterianas. Dessa forma, sedimentos finos podem apresentar maiores densidades de bactérias, inclusive pato- 
gênicas, determinando sua sobrevivência no ambiente, o que poderia explicar as elevadas densidades de bactérias observadas nos grãos de areia fina das Praias do Gonzaguinha e da Ilha Porchat.

Outros fatores de influência na colonização dos grãos de sedimento, que determinam tanto a distribuição quanto as densidades de microrganismos nos sedimentos, são sua quantidade e a

\section{REFERÊNCIAS} mento técnico) and seawater along Tel Aviv coast. MAP Tech Rep Ser. 1994;87:65-81. Oahu, Hawaii. Water Sci Technol. 1995;31:251-4. stream. Arch Hydrobiol. 1999;146(2):189-217. pond systems. J Appl Microbiol. 2000;89(2):349-60. 2006. /WEF; 1999.

11. Suguio K. Introdução à sedimentologia. São Paulo: EDUSP; 1973. técnica NM 248, de 2003. patogênicos na água do mar consiste em uma ameaça à saúde dos banhistas. Prieto, et $\mathrm{al}^{34}$, em um estudo nas praias de Santander, Espanha, demonstraram que o aumento na densidade de coliformes fecais ocasionou maior ocorrência de doenças de veiculação hídrica, principalmente gastroenterites.

\section{CONCLUSÃO}

O presente estudo demonstra a necessidade de estabelecimento de programas de monitoramento para areias de praias visto que atualmente a avaliação da qualidade das praias é parte importante de programas de gerenciamento costeiro integrado. Além disso, informações quantitativas sobre a concentração de patógenos no ambiente permitem uma melhor avaliação de áreas costeiras do ponto de vista de saúde pública.

1. Brasil. Ministério da Saúde. Monitorização das Doenças Diarreicas Agudas. CENEPI / FUNASA / MS; 1999. 4 v. (Docu-

2. Saliba LJ, Helmer R. Health risks associated with pollution of coastal bathing Waters. World Health Stat Q. 1990;4:177-87.

3. Ghinsberg RC, Leibowitz P, Witkin H, Mates A, Seinberg Y, Bar DL, et al. Monitoring selected bacteria and fungi in sand

4. Oshiro R, Fujioka R. Sand, soil and pigeon droppings: sources of indicator bacteria in the waters of Hanauma Bay,

5. Brunke M, Fischer H. Hyporheic bacteria-relationships to environmental gradients and invertebrates in a prealpine

6. Davies-Colley RJ, Donnison AM, Speed DJ, Ross CM, Nagels JW. Inactivation of fecal indicator microorganisms in waste stabilization ponds: interactions of environmental factors with sunlight. Water Res. 1999;33(5):1220-30.

7. Davies CM, Bavor HJ. The fate of storm water associated bacteria in constructed wetland and water pollution control

8. Brasil. Conselho Nacional do Meio Ambiente (CONAMA). Resolução n. 274, de novembro de 2000.

9. CETESB (São Paulo). Relatório de qualidade das águas litorâneas do Estado de São Paulo: balneabilidade das praias.

10. American Public Health Association. Standard Methods for the Examination of Water and Wastewater. APHA / AWWA

12. Associação Brasileira de Normas Técnicas (ABNT). Agregados: determinação da composição granulométrica. Norma

13. Dean WE. Determination of carbonate and organic matter in calcareous sediments and sedimentary rocks by loss on ignition: comparision with other methods. J Sed Petrol. 1974;44:242-8.

14. Anderson IC, Rhodes M, Kator H. Sublethal stress in Escherichia coli: a function of salinity. Appl Environ Microbiol 1979;38:1147-52.

15. Sinton LW, Hall CH, Lynch PA, Davies-Colley RJ. Sunlight inactivation of fecal indicator bacteria and bacteriophages from waste stabilization pond effluent in fresh and salinity waters. Appl Environ Microbiol. 2002;68:112-31.

16. Dyer KR. The measurement of fluxes and flushing times in estuaries. Proc Rev Work. 1981:26-30.

17. Colwell RR, Belkin S. Oceans and Health: Pathogens in the Marine Environment. USA: Springer; 2006.

18. Shibata T, Solo-Gabriele HM, Fleming LE, Elmir S. Monitoring marine recreational water quality using multiple microbial indicators ins a urban tropical environment. Water Res. 2004;38:3119-31. 
19. Oliveira AJFC, Holnaggel HC, Mesquita HSL, Fontes RFC. Physical, chemical, and microbiological characterization of the intertidal sediments of Perequê Beach, Guarujá-SP, Brazil. Mar Poll Bull. 2007;54:921-7.

20. Gould DJ, Munro D. Relevance of microbial mortality to outfall design. Coastal Discharges. 1981;45-50.

21. Evison LM. Comparative studies on the survival of indicator organisms and pathogens in fresh and sea water. Water Sci Technol. 1988;20:309-15.

22. Davies CM, Evison LM. Sunlight and the survival of enteric bacteria in natural waters. J Appl Bacteriol. 1991;70:265-74.

23. Elmanama AA, Fahd MI, Afifi S, Abdallah S, Bahr S. Microbiological beach and sand quality in Gaza Strip in comparison to seawater quality. Environ Res. 2005;99:1-10.

24. Bonilla TD, Nowosielski K, Cuvelier M, Hartz A, Green M, Esiobu N, et al. Prevalence and distribution of fecal indicator organisms ins South Florida beach sand and preliminary assessment of health effects associated with beach sand exposure. Mar Poll Bull. 2007;54(9):1472-82.

25. Whitman RL, Nevers MB. Foreshore sand as a source of Escherichia coli in near shore water of a Lake Michigan beach. Appl Environ Microbiol. 2003;69(9):5555-62.

26. Burton GA, Gunnison DJ, Lanza GR. Survival of pathogenic bacteria on various freshwater sediments. Appl Environ Microbiol. 1987;53:633-8.

27. Chan YY, Killick EG. The effect of salinity, light and temperature in a disposal environment on the recovery of E. coli following exposure to ultraviolet radiation. Water Res. 1995;29(5):1373-7.

28. Darakas E. E coli kinetics: effect of temperature on the maintenance and respectively decay phase. Environ Monit Assess. 2002;78:101-10.

29. Laliberte P, Grimes DJ. Survival of Escherichia coli in lake bottom sediments. Appl Environ Microbiol. 1982;43(3):623-8. 30. Alm EW, Burke J, Spain A. Fecal indicator bacteria are abundant in wet sand at freshwater beaches. Water Res. 2003;37(16):3978-82.

31. Sato MIZ, Bari MD, Lamparelli CC, Truzzi AC, Coelho MCLS, Hachich EM. Sanitary quality of sands from marine recreational beaches of São Paulo, Brazil. Braz J Microbiol. 2005;36(4):321-6.

32. Oliveira AJFC, Pinhata JMW. Antimicrobial resistance and species composition of Enterococcus spp. isolated from waters and sands of marine recreational beaches in Southeastern Brazil. Water Res. 2008;42:2242-50.

33. Crapez MAC. Bactérias Marinhas. In: Pereira RC, Soares-Gomes A, organizadores. Biologia Marinha. Rio de Janeiro: Interciência; 2002. p. 84-101.

34. Prieto MD, Lopez B, Juanes JA, Revilla JA, Llorca J, Rodriguez-Delgado M. Recreational in coastal Waters: health risks associated with bathing in sea water. J Epidemiol Comm Health. 2006;55:442-7. 